\title{
Directions for the Rational Use of Additional Organic and Mineral Resources of Peat Deposits
}

\author{
Oleh Misnicow ${ }^{1, *}$, and Alexandr Iablonev ${ }^{1}$ \\ ${ }^{1}$ Tver State Technical University, A. Nikitin Street, 22, 170026, Tver, Russia
}

\begin{abstract}
The article discusses the issues of insufficient use of organic and mineral resources of peat deposits (substandard peat, mineralised sapropel, wood inclusions of peat deposit, organomineral deposits, etc.). The authors propose a structural scheme of directions of processing and use of organic and organomineral biogenic resources. It includes obtaining various types of composite formed materials for their application in four main directions: energy, agricultural production, environmental protection, and construction industry. Mineral clay components improve the ability of composite materials to be shaped by extrusion and pelletising methods. Some of them also have catalytic activity, which is the basis for their use in thermochemical processing. In peat raw materials, subjected to the process of self-heating during the storage, there is a change of the group chemical composition with the formation of hydrophobic compounds (termobitums). This opens up additional perspectives of their extraction and usage for hydrophobic modification of mineral disperse materials. The classification of industrial wastes and organomineral resources of peat deposits according to the required qualitative characteristics with the indication of possible directions of additional processing is presented in the paper.
\end{abstract}

\section{Introduction}

The Russian Federation has enormous reserves of energy resources. Combustible minerals occupy a special place among them, the main ones being gas, oil and coal, which serve both as fuel and raw materials for chemical processing to the national economy, as well as to CIS and other foreign countries. Due to a certain scarcity of conventional energy resources, primarily natural gas, in some regions of Russia, there have been recent recommendations to make greater use of local raw materials in the energy sector. Local energy resources include peat, oil shale and various types of biomass. In addition to peat, there are considerable stocks of biomass (swamp vegetation and wood residues in peat deposits) on the territories of peat deposits that are developed and suitable for industrial development.

The use of modern technologies of peat harvesting [1] and processing [2], results in the fact that up to 30-35\% (and sometimes more) of peat raw materials are attributed to losses and practically not extracted. And often these losses are caused not so much by the conditions of peat deposits, as by the absence of technologies for processing its off-balance reserves. The problem of the use of other organic and mineral resources of peat bogs is even more

* Corresponding author: oleg.misnikov@gmail.com 
acute. These include sapropels of high mineralisation, clays and clay marls, which are under the peat deposit or in adjacent areas. In addition to these, due to the irregularities of the bog bed, a layer of peat has to be left unharvested, as it will have a higher ash content and will not meet the requirements of modern standards.

For example, according to the data of the geological exploration in the Tver region (a typical region of Central Russia) there are about fifteen deposits with the identified reserves of sapropel and organomineral deposits under the peat deposit layer. Their quantitative and qualitative composition [3] shows that losses of resources of peat deposits make from 18 to $52 \%$ at the expense of the off-balance reserves of peat raw materials, wood residues and not extracted organomineral deposits. The ratio is roughly the same in other deposits in the Central Economic Region of the Russian Federation. Currently, this economic area has reserves of sapropels under the peat deposit of about 14 million tonnes, and reserves of organomineral deposits of about 15.5 million tonnes.

In addition, during peat harvesting a considerable amount of wood residues is extracted from the deposit, which are stored in special stacks in field warehouses. It is known that depending on stumpiness of the deposit up to $300 \mathrm{~m}^{3}$ stumps are extracted from 1 hectare of new area, and during maintenance of production fields - approximately $100-150 \mathrm{~m}^{3} / \mathrm{ha}$. The volume of individual stump storage units can reach more than $1000 \mathrm{~m}^{3}$. The system for utilisation of wood residues extracted from the deposit is almost non-existent, due to the comparatively small set of environmentally balanced recycling technologies. In the best case scenario the wood waste is fractionated, cut up (sawed) and incinerated at public utility companies. Therefore, the volume of stump wood usage is still significantly lower than the volume of its extraction from the deposit.

It is clear that this amount of dry woody residues is an additional (together with peat) stock of organic matter on the surface of the harvesting fields, and thus poses a great danger of fire in the peat deposit and its surrounding areas. But the main combustible material in peat deposits is harvested peat. The potential danger of peat as a combustible material depends on its moisture content and increases as the moisture content decreases, determining its ability to ignite $[4,5]$.

In almost all countries with a well-developed peat industry [1], the main method of extracting raw materials is to obtain milled peat, followed by field drying and harvesting in large storage units (stacks). One of the main disadvantages of milled peat is its ability to selfheat during storage. During self-heating, the components of the organic matter of peat undergo significant changes. According to [6], during the heating of peat in a stack, the content of bituminous substances in its organic matter increases by $50 \%$, humic substances (humic and fulvic acids) by $44 \%$, at the same time, the content of cellulose decreases by 40 $\%$ and hemicellulose by $10 \%$. At the late stage of storage, when the process of peat selfheating has deeply developed and «semi-coke» has formed in the stack core, the access of air oxygen to the active zone is inevitably connected with the rapid course of the oxidation reaction of "semi-coke» and its spontaneous combustion. For this reason, it is necessary to leave such stacks in the field without being dispatched. In this case, self-heating processes continue in the stack and cause mineralisation of the peat organic matter. The loss of organic matter from self-heating peat ranges from 1-2 \% to 5-10\% per month (depending on the temperature) [6]. After the finish of these processes and the decrease in temperature, the peat can be transported to the consumer, but the value of the raw material is noticeably reduced when used as an energy fuel or for traditional chemical processing.

This issue was partially solved in the period of the active use of peat in agriculture, since the thermal destruction of organic components during self-heating provides activation of peat nitrogen $[7,8]$, which can be used as a fertiliser. As a result of the activity of thermobacteria and thermochemical processes occurring during the storage of peat in stacks, there is a transformation of the hard-to-reach nitrogen, bound with the organic matter, into easily 
assimilated by plants forms $[9,10]$. However, at present, the lack of resources of agricultural producers does not allow large-scale sales of self-heated peat stacks.

Thus, one of the main problems facing the peat industry is the development of integrated, ecologically-balanced technologies for harvesting and processing the maximum possible amount of organic and organomineral resources found in a peat deposit.

\section{Review}

A promising direction for the use of standardised peat, sapropels of varying degrees of mineralisation, clay raw materials, as well as industrial waste of their extraction (peat, subjected to self-heating during storage, wood residues of the peat deposit) is their processing using pre-forming, both in «pure» form, and in the form of two- or multi-component organicmineral compositions (Fig. 1).

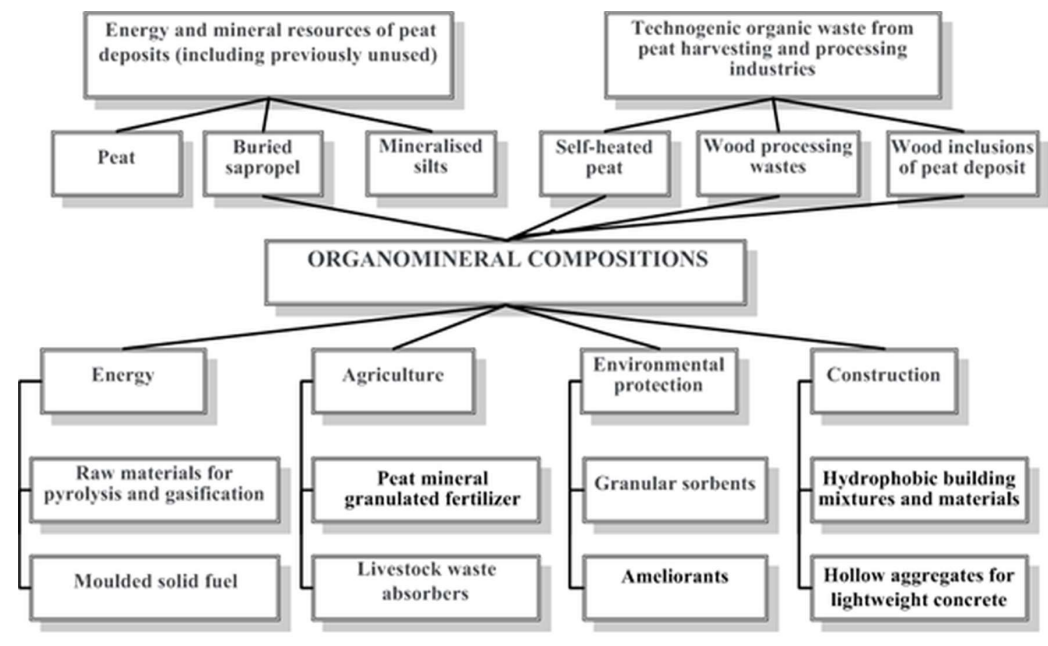

Fig. 1. Possible areas of recycling and utilisation of organic and organomineral biogenic resources.

Forming by pelletizing or extrusion of pre-moistened compositions, followed by drying to equilibrium moisture content, is preferred among all known types of forming. When the formed highly-dispersed materials are dried, structure-forming processes occur, leading to an increase in the system strength $[11,12]$. The description of structure formation processes in disperse systems is complicated by the diversity of their composition and properties. Changes in a structured system are believed to be due to the ability of dispersed particles to move in the dispersion medium [13], and depend mainly on their concentration, shape, size, and nature of the interaction forces. But this approach can primarily be applied to monocomponent systems consisting of materials of the same nature. In organomineral materials, the type and concentration of the organic and/or mineral constituents will have an enormous influence. Moreover, in natural conditions it is extremely rare to find disperse systems consisting only of organic or only of mineral components. Mostly we have to deal with their mixtures (compositions).

Even a bio-resource such as peat, which is traditionally classified as organic material, is in some cases an organomineral composition. So here it is more correct to speak about the predominant action of the organic or mineral part. More complicated structure-forming processes take place during drying of sapropel [11], since the range of their ash content (in terms of dry matter) $A^{\mathrm{d}}$ is much wider, from $A^{\mathrm{d}}=0$ (theoretically) to $A^{\mathrm{d}}=85-90 \%$. In general, the processes of disturbance of aggregative stability of disperse systems leads to 
their separation into macrophases or to the development of a spatial grid in the volume of the system. This causes the transition of the free disperse system into the bonded disperse system, in which bonding forces in the contacts between the particles are sufficiently large to withstand thermal movement and external force influences [11].

It is proposed to use the obtained formed materials (Fig. 2) in four main directions: energy, agriculture, environmental protection and construction production (Fig. 1).

\subsection{Energy}

For the energy-related use of resources of peat deposits it is proposed to produce composite formed solid fuel or raw material for pyrolysis (gasification). The study of moisture content distribution in the formation of peat-mass (one of the initial stages of solid fuel production) depending on the average diameter of the pellets (Fig. 2) revealed a tendency to increase the initial moisture content when increasing their diameter. The increased moisture content in the pellets is determined by thicker hydrate films formed between the particles of the solid phase of the material.
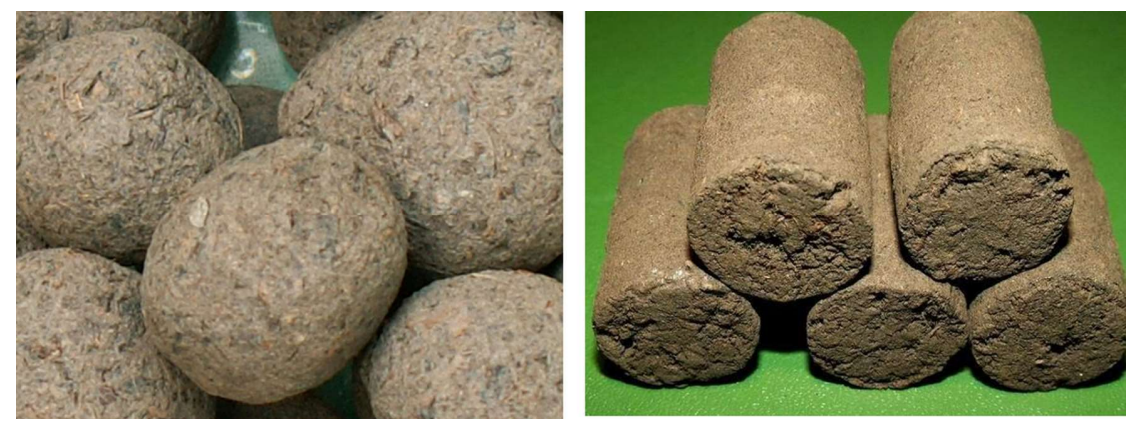

Fig. 2. Peat-based formed products: spherical (left) and cylindrical (right) pellets.

When considering the process of formation of pellets from mixtures, it was taken into account that the growth of particle diameter is possible only if there are active binder centres on the surface, with which the particles of bulk material can interact [14]. For the «pure» peat-containing materials, due to less plasticity of the structure, the binder can be brought to the surface only after a large number of collisions of particles with each other or with the board of the pelletizer. Therefore, the formation of the pellet will take place at a minimum for this mode of hydrate films.

For the compositions in which the additional binder is clay (clay material), the build-up of surface layers will be possible with fewer impacts of pellets against the board, and consequently with a higher value of the liquid phase in the pore space (as compared to a stable film thickness).

A similar formation pattern of organomineral materials can be observed when using the extrusion method. In other words, it is also possible to carry out the process at a moisture content lower than in the «pure» peat systems, with a simultaneous improvement of their quality (no cracks at the outlet of the moulding device). The relative moisture content reduction in comparison with the original peat lies in the range from 0 to $37 \%$ depending on the concentration of the mineral component. The type of clayey material does not usually influence this process (Fig. 3). 


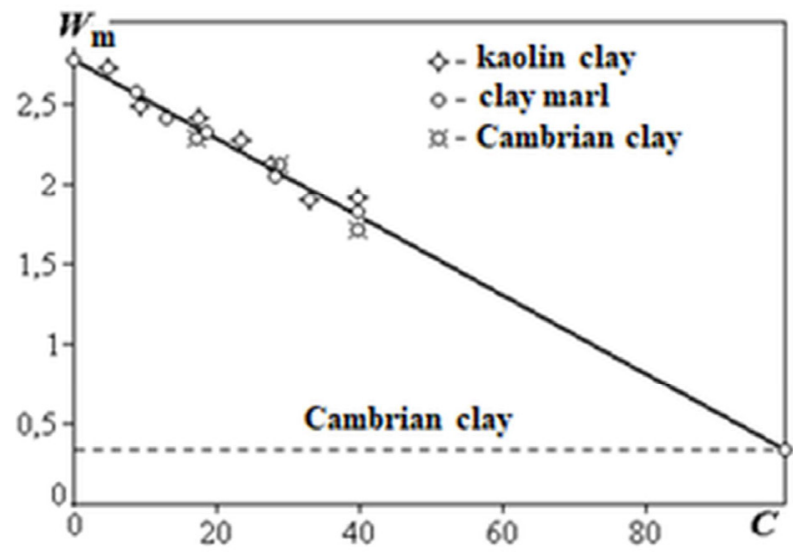

Fig. 3. Generalised dependence of formation moisture content $W_{\mathrm{m}}, \mathrm{kg} / \mathrm{kg}$ of compositions on the content of mineral components $C, \%$ (kaolin and Cambrian clay, clay marl).

It should be noted that the violation of integrity during the formation of a peat lump (pellet) has always been a fairly significant problem for the technology of peat production $[15,16]$. Nowadays this problem is still relevant for the milling method of peat lump formation in the field: when forming peat with reduced moisture content (layer-by-layer or fine-slot milling), the lumps will have transverse cracks or even break when coming out of the nozzles. The reasons for this are the lack of water for the formation of water films, which bind the peat structure through capillary forces, and the high content of the gas phase, which separates the structural formations. As a result, such peat, which deforms intensively during its passage through the forming unit channel, expands after leaving it and forms transverse cracks and signs of annular «ruffling» (Fig. 4).

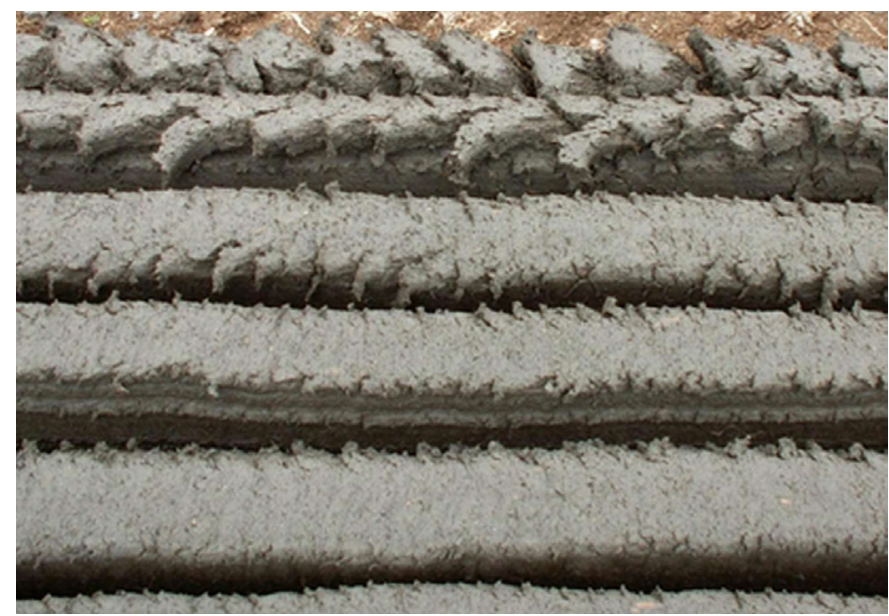

Fig. 4. Freshly-formed peat belt with obvious signs of annular «ruffing» (top).

In addition to the structure-forming function many types of clay additives have catalytic activity [18]. In their presence, during low-temperature thermochemical decomposition of organic matter of peat the volume of combustible gas increases by 1.1-1.4 times depending on the type of mineral component. Positive results are observed when using bentonite (Sarigiukh deposit, Armenia) and Cambrian (Chekalov deposit, Leningrad Region) clays, as well as clay marl (Terelesovo-Gryadskoe peat deposit, Tver Region). In some cases, in order 
to enhance the effectiveness of natural clay materials it is suggested to increase their concentration up to $20 \%$ and more (with the subsequent use of a solid residue as a sorption material). This makes it possible to double the volume of the pyrolysis gases. Clay minerals introduced into the mixture, in addition to the volume of pyrolysis gases noticeably increase the volume of released hydrocarbons. Their values are more than 2 times higher than the values obtained in the pyrolysis of peat samples not containing natural catalysts.

\subsection{Environment protection}

When carrying out activities related to the protection of the environment from the negative anthropogenic impact, it is proposed to use granular (usually spherical) composite sorbents [19]. Physico-chemical models reflecting the processes of sorption [20-23] suggest that the change of the characteristics of materials can be performed in two directions: varying the porous structure of the material and (or) regulating the physico-chemical and chemical properties of the reacting sorbent surface. The second group may include transformation of ion-exchange properties of the peat matrix [19]. The requirements for the porosity of the sorbent may beinitially taken into account when choosing the raw material with the optimum structure. In this case, the conditions of formation of peat in natural conditions and the scheme of its harvesting should be taken into account. Adjustment of the ion-exchange properties is more appropriate in the process of obtaining the finished product. Here, the parameters on the degree of dispersion of peat, the method of granulation and modification (physico-chemical, thermal, chemical effects or their combination) should be provided.

The analysis of experimental studies of the absorption capacity of peat [19], made it possible to establish the maximum value of water absorption in 48 hours of exposure to aqueous medium for all types of sorption solutions. The best water absorption values correspond to the samples with the lowest degree of decomposition, which is due to the large value of the pore space volume. This means that the primary regulation of the sorption properties of peat and composite systems can be realised by selecting the material with the highest content of plant residues. These include the production residues such as peat waste layer, inclusions of cotton-grasses, mosses and woody residues. At the same time, the harvesting and processing technology must have a minimal disruptive effect on the structure of the native raw material.

The analysis of scientific sources [19-23] shows that the characteristics of peat sorbents for oil products removal allow them to successfully compete with other types of materials, having comparable values of absorption capacity and advantages in economic and ecological indicators. In addition, peat products are distinguished by a high degree of purification, ease of recycling and the possibility of producing selective sorbents, as well as the ability to remain on the water surface for a long time (more than one month). And after selective sorption of liquid hydrocarbons, the material (sorbent-sorbate system) forms an even more stable floating conglomerate [19], which can be relatively easily removed from the water surface and sent for recycling, including by low-temperature catalytic pyrolysis (gasification) [24].

\subsection{Construction}

In the construction industry, wastes from peat harvesting and processing can be used for the production of hydrophobic modifiers [6], hollow aggregates for lightweight concrete [25], building materials with different types of peat components [26-30], and bitumen retaining additives in crushed-mastic asphalt concrete [31].

The results of studies [6] have established that special hydrophobic additives extracted from organic raw materials, including peat, which undergoes processes of self-heating during 
storage in stacks, as well as waste wood processing can be used to increase the shelf life of mineral binders. Special attention should be paid to the fact of increasing the yield of a group of substances extracted by organic solvents during peat self-heating. They are called pyrobitum (termobitum) [6], which marks the connection of their appearance with the influence of heat. Thus, the peat, which has undergone the process of self-heating (industrial waste), should have better characteristics as an initial raw material for the production of hydrophobic additives compared with the standardised organic materials.

Based on the analysis of the properties of plant biomass, it was established that many types of wood exceed the content of extractable organic solvents in some types of peat. This also predetermines the possibility of their application in the production of hydrophobicmodifying additives. Low-temperature heat treatment of wood leads to the sublimation of volatile resinous compounds, which are used to create a hydrophobic shell on the grains of mineral particles. The special properties of stump wood, extracted from peat deposits, also allow its use as raw material for the production of hydrophobic additives. Anaerobic decomposition of this wood was prevented by acidic environment and antiseptic properties of peat deposits, and the main representatives of woody vegetation of highland deposits are coniferous tree species (first of all, pine). The efficiency of the developed method of hydrophobic modification is very high, and in a number of characteristics it exceeds the indicators obtained with the use of traditional mineral and organic modifiers.

Hollow aggregate obtained from unused resources and wastes of peat production fully meets the basic requirements for artificial porous aggregates. It has comparatively low bulk density, uniform shape and sufficient strength to produce lightweight concrete.

\section{Conclusions}

Thus, the generalisation of the results of scientific research presented in the article has made it possible to systematise (classify) the main directions of processing of organic and organomineral resources of peat deposits, as well as industrial waste generated during the harvesting and processing of peat with differentiation by type (table 2), which significantly increases the efficiency of their additional utilization.

Table 2. Directions for additional processing of industrial waste and organomineral resources of peat deposits.

\begin{tabular}{|c|c|l|l|}
\hline $\begin{array}{c}\text { Type of } \\
\text { resource } \\
\text { (industrial } \\
\text { waste) }\end{array}$ & \multicolumn{1}{|c|}{$\begin{array}{c}\text { Basic characteristics of raw } \\
\text { materials }\end{array}$} & \multicolumn{1}{|c|}{$\begin{array}{c}\text { Possible direction of application } \\
\text { (additional recycling) }\end{array}$} \\
\hline \multirow{2}{*}{1} & $\begin{array}{l}\text { Bog, transitional, fen type; } \\
\mathrm{R}_{\mathrm{P}}=5-15 \% ; \mathrm{A}^{\mathrm{d}}=15-40 \%\end{array}$ & $\begin{array}{l}\text { Formed organomineral sorption } \\
\text { materials }\end{array}$ \\
\cline { 2 - 4 } $\begin{array}{c}\text { Off- } \\
\text { balancepeatrese } \\
\text { rves }\end{array}$ & $\begin{array}{l}\mathrm{Bog}, \text { transitional, fen type; } \\
\mathrm{R}_{\mathrm{P}}>15 \% ; \mathrm{A}^{\mathrm{d}}=15-40 \%\end{array}$ & $\begin{array}{l}\text { Formed organomineral fuel (semi- } \\
\text { finished product for thermochemical } \\
\text { processing) }\end{array}$ \\
\cline { 2 - 4 } 2 & $\begin{array}{l}\text { Bog, transitional, fen type; } \\
\mathrm{R}_{\mathrm{P}}>25 \% ; \mathrm{A}^{\mathrm{d}}=15-40 \%\end{array}$ & $\begin{array}{l}\text { Raw materials for the production of } \\
\text { hydrophobic-modifying additives in } \\
\text { mineral binders }\end{array}$ \\
\hline $\begin{array}{c}\text { Peat that has } \\
\text { undergone self- } \\
\text { heating }\end{array}$ & $\begin{array}{l}\text { Bog, transitional, fen type; } \\
\mathrm{R}_{\mathrm{P}}>10 \% ; \\
\text { increased content of bitumen } \\
\text { and humic substances }\end{array}$ & $\begin{array}{l}\text { Organic binder for composite } \\
\text { materials, additives for crushed- } \\
\text { mastic asphalt concrete }\end{array}$ \\
\hline
\end{tabular}




\begin{tabular}{|c|c|c|c|}
\hline & & $\begin{array}{l}\text { Bog, transitional, fen type; } \\
\mathrm{R}_{\mathrm{P}}>25 \% \text {; } \mathrm{A}^{\mathrm{d}}<23 \% ; \\
\text { increased content of bitumen } \\
\text { and humic substances }\end{array}$ & $\begin{array}{l}\text { Raw materials for the production of } \\
\text { hydrophobic-modifying additives in } \\
\text { mineral binders }\end{array}$ \\
\hline \multirow{2}{*}{3} & \multirow{2}{*}{$\begin{array}{l}\text { Waste from peat } \\
\text { production and } \\
\text { wood } \\
\text { processing }\end{array}$} & $\begin{array}{l}\text { Wood residues extracted from a } \\
\text { peat deposit; } \mathrm{A}^{\mathrm{d}} \text { up to } 5 \% \text {; } \\
\text { bitumen content up to } 20 \%\end{array}$ & \multirow{2}{*}{$\begin{array}{l}\text { Raw material for the production of } \\
\text { hydrophobic-modifying additives in } \\
\text { mineral binders; } \\
\text { Organic component in formed solid } \\
\text { fuels (semi-finished product for } \\
\text { thermal processing) }\end{array}$} \\
\hline & & $\begin{array}{l}\text { Sawdust (wood processing } \\
\text { waste); } \mathrm{A}^{\mathrm{d}} \text { up to } 0.5 \% \text {; up to } 6 \\
\% \text { extractable substances }\end{array}$ & \\
\hline \multirow[b]{2}{*}{4} & \multirow{2}{*}{$\begin{array}{c}\text { Buried } \\
\text { sapropels }\end{array}$} & Organic type, $\mathrm{A}^{\mathrm{d}<30 \%}$ & $\begin{array}{l}\text { Raw material for low temperature } \\
\text { pyrolysis and gasification; } \\
\text { Organic binder for composite } \\
\text { materials }\end{array}$ \\
\hline & & $\begin{array}{l}\text { Carbonate, silica, mixed types; } \\
\mathrm{A}^{\mathrm{d}} \text { up to } 85 \% \text {; presence of } \\
\text { catalytically active elements }\end{array}$ & $\begin{array}{l}\text { Organomineral binder for composite } \\
\text { materials; } \\
\text { Catalytic additive for low } \\
\text { temperature pyrolysis and } \\
\text { gasification }\end{array}$ \\
\hline \multirow[b]{2}{*}{5} & \multirow{2}{*}{$\begin{array}{l}\text { Organomineral } \\
\text { deposits and } \\
\text { clay materials }\end{array}$} & $\mathrm{A}^{\mathrm{d}}$ up to $100 \%$ & $\begin{array}{l}\text { Hydrophilic additives in formed } \\
\text { organomineral sorbents }\end{array}$ \\
\hline & & $\begin{array}{l}\mathrm{A}^{\mathrm{d}} \text { up to } 100 \% \text {, presence of } \\
\text { catalytically active elements }\end{array}$ & $\begin{array}{lcc}\text { Catalytic } & \text { additive for } & \text { low } \\
\text { temperature } & \text { pyrolysis } & \text { and } \\
\text { gasification } & & \end{array}$ \\
\hline
\end{tabular}

Depending on the resource or industrial waste available in the peat deposit area, the required characteristics of the raw material to be processed for a particular application are given.

\section{References}

1. O. Misnikov, E3S Web Conf. 41, 01046 (2018)

2. I. Lishtvan, V. Dudarchik, V. Kraiko, E. Anufrieva, N. Bulgakova Proceedings of the National Academy of Sciences of Belarus, Chemical Series, 56:2, 212-219 (2020)

3. I. Lishtvan, V. Dudarchik, V. Kraiko, E. Anufrieva, E. Smolyachkova, Solid Fuel Chemistry, 51:5, 278-285 (2017)

4. K. Widyastuti, M. Imron, S. Pradopo, H. Suryatmojo, B. Sopha, A. Spessa, U. Berger, International Journal of Wildland Fire, 30:2, 71-89 (2021)

5. Y. Hu, W. Cui, G. Rein, Fire Safety Journal, 113, 102940 (2020)

6. O. Misnikov, Mires and Peat, 18:22, 1-15 (2016)

7. I. Lishtvan, Y. Yanuta, A. Abramets, V. Strigutskii, Y. Navosha, Solid Fuel Chemistry, 47:3, 147-152 (2013)

8. K Woli, J. Pantoja, J. Sawyer, Communications in Soil Science and Plant, 47:22, 2558$2572(2016)$

9. L. Mueller, G. Shepherd, U. Schindler, B. Ball, L. Munkholm, V. Hennings, E. Smolentseva, O. Rukhovic, Soil and Tillage Research, 127, 74-84 (2013) 
10. M. Rajaie, A. Tavakoly, International Journal of Recycling of Organic Waste in Agriculture, 5:4, 339-347 (2016)

11. A. Afanas'ev, O. Misnikov, Theoretical Foundations of Chemical Engineering, 37:6, 620-629 (2003)

12. A. Afanas'ev, A. Efremov, Theoretical Foundations of Chemical Engineering, 45:1, 120$126(2011)$

13. N. Gamayunov, S. Gamayunov, Eurasian Soil Science, 38:3, 297-304 (2005)

14. C. Lau, Q. Yu, V. Lister, S. Rough, D. Wilson, M. Zhang, Chemical Engineering Research and Design, 92:11, 12413-2424 (2014)

15. V. Belyakov, A. Kuporova, E3S Web Conf. 41, 01047 (2018)

16. V. Belyakov, A. Kuporova, E3S E3S Web Conf. 174, 01008 (2020)

17. K. Chalov, Y. Lugovoy, Y. Kosivtsov, M. Sulman, E. Sulman, V. Matveeva, A. Stepacheva, Bulletin of Chemical Reaction Engineering and Catalysis, 11:3, 330-338 (2016)

18. O. Misnikov, A. Timofeev, O. Pukhova, Polymer Science. Series D, 8:1, 66-74 (2015)

19. N. Gamayunov, B. Maslennikov, Y. Shul'man, Eurasian Soil Science, 24:4, 122-126 (1992)

20. L. Ansone-Bertina, M. Klavins, Open Chemistry, 14:1, 46-59 (2016)

21. C. Zheng, S. Feng, P. Liu, E. Fries, Q.Wang, Z. Shen, H. Liu, T. Zhang, Clean - Soil, Air, Water, 44:9, 1163-1173 (2016)

22. A. Robalds, L. Dreijalte, O. Bikovens, M. Klavins, Desalination and Water Treatment, 57:28, 13285-13294 (2016)

23. E. Sulman, Yu. Kosivtsov, M. Sulman, V. Alfyorov, Yu. Lugovoy, K. Chalov, O. Misnikov, A. Afanasjev, N. Kumar, D. Murzin, IInd International Conference on Fundamental and Applied Sciences, 1482, 595-598 (2012)

24. B. Thomas, J. Yang, K. Mo, J. Abdalla, R. Hawileh, E. Ariyachandra, Journal of Building Engineering, 40, 102332 (2021)

25. N. Mitina, V. Lotov, N. Kopanitsa, Izvestiya Vysshikh Uchebnykh Zavedenii, Seriya Khimiya I Khimicheskaya Tekhnologiya, 61:8, 81-88 (2018)

26. N. Kopanitsa, Y. Sarkisov, A. Gorshkova, O. Demyanenko, AIP Conference Proceedings, 1698, 070015 (2016)

27. N. Kopanitsa, A. Kudyakov, M. Kovaleva, G. Kopanitsa, IOP Conference Series: "Materials Science and Engineering", 71:1, 012011 (2015)

28. N. Kopanitsa, Y. Sarkisov, A. Ryzhikov, Stroitel'nye Materialy, 7, 12-14 (2002)

29. K. Fedor, B. Vladimir, Solid State Phenomena, 309, 120-125 (2020)

30. O. Misnikov, E3S Web Conf. 174, 01024 (2020) 